\title{
QS-9000: A ISO já Não é o Bastante
}

\section{Cristiano Rocha Heckert}

Aluno de graduação - Grupo de Pesquisa em Qualidade e Produtividade - Depto. Engenharia de Produção EPUSP - Cidade Universitária, CP 8174, CEP 05508-900, São Paulo - SP, Fone (011)889-9669

\section{Paulino Graciano Francischini}

Prof. Dr. Depto. Engenharia de Produção, EPUSP - Cidade Universitária, CP 8174, CEP 05508-900, São Paulo - SP. Grupo de Pesquisa em Qualidade e Produtividade

\section{Roberto G. Rotondaro}

Prof. Dr. Depto. Engenharia de Produção, EPUSP - Cidade Universitária, CP 8174, CEP 05508-900, São Paulo - SP. Grupo de Pesquisa em Qualidade e Produtividade

Palavras chaves: QS-9000, ISO 9000, norma de qualidade, indústria automobilística

Key words: QS-9000, ISO 9000, quality standard, automotive industry.

\section{RESUMO:}

O objetivo deste artigo é apresentar e analisar a nova norma de Sistema de Garantia da Qualidade para o setor automobilistico, QS-9000, a qual foi desenvolvida pelas três grandes montadoras norte-americanas: Chrysler, Ford e GM. Descreveremos a QS-9000, fazendo uma comparação desta com a série ISO 9000, na qual ela está baseada, e analisando os novos conceitos, como a "melhoria continua", que são introduzidos nela. Em seguida, faremos algumas considerações sobre como está sendo conduzido o processo de implementação da QS-9000 e o que as empresas brasileiras têm feito para se inserir neste novo contexto.

\section{ABSTRACT:}

This paper aims to discuss the new quality standard for the automotive industry, QS-9000, which is sponsored by the American "Big Three": Chrysler, Ford and GM. It describes QS-9000 in comparison with the ISO 9000 standards, on which the first is based. The new concepts that are introduced in this standard, specially the notion of "continous improvement", are also analysed. Then it considers how the process of implementing QS-9000 is being held throughout the world and how it will affect the automotive sector. Finally, it is discussed how Brazilian companies are preparing to take part in this movement. 


\section{PRODUÇÃO}

\section{Introdução e justificativa}

A QS-9000 surgiu de um esforço das três grandes empresas automobilisticas norte-americanas, Chrysler, Ford e GM, no sentido de criar um padrão unificado de sistema da qualidade para o setor.

Em 1988, durante a Conferência da Divisão Automotiva da American Society for Quality Control (ASQC), foi criada a "Task Force". Este órgão seria o responsável por conduzir o processo de unificação dos padrões de qualidade das três grandes. Assim, do trabalho da Task Force, surgiu, em 1990, o Manual de Sistemas de Medição (MSA), seguido do Manual de Referência sobre o Controle Estatístico de Processo (CEP,1991), e do Processo de Aprovação da produção de peças (PPAP), Failure Mode Effect Analysis (FMEA) e Advanced Process Quality Planing (APQP), em 1992-1994. Finalmente, em 1995, foram lançados a QS-9000 e o QSA (Quality System Auditing).

O objetivo de todo este processo foi fazer com que seus fornecedores, muitas vezes comuns às três empresas, adotassem uma única norma de qualidade. Assim, elas pretendiam baratear seus custos com atividades de inspeção e auditoria e também atender a uma antiga reivindicação dos fornecedores.

Além das três montadoras, diversos produtores de caminhão também estão empregando esta norma, a qual, como o próprio nome sugere, baseia-se na mundialmente reconhecida série ISO 9000. Partindo da norma ISO 9001, foram feitas algumas adaptações e acréscimos para adequá-la à realidade das indústrias de automóveis. Como a adoção da QS9000 é compulsória a todos os fornecedores diretos, externos e internos, das três montadoras, espera-se uma grande corrida nesse sentido para os próximos anos, não só nos Estados Unidos, mas também em todos os lugares do mundo onde elas estão instaladas, inclusive no Brasil.

Este trabalho buscará, portanto, analisar com mais detalhes a QS-9000, fazendo uma comparação desta com a série ISO 9000 , mais precisamente, com a norma ISO 9001. Primeiramente, será feita uma revisão teórica, observando quais são os pontos comuns entre as normas e quais os requisitos específicos para o setor automobilístico acrescentados na QS-9000. Serão estudados, ainda, os impactos que a introdução desta norma trará para a qualidade nas indústrias automobilisticas a nível mundial e também no Brasil. Por fim, observaremos o que as empresas brasileiras têm feito para adequar-se a esta nova realidade.

\section{QS-9000 x ISO 9000: Semelhanças e diferenças}

A QS-9000 tem como base a norma ISO 9001 , a mais ampla da série ISO 9000 , pois abrange as atividades de projeto, desenvolvimento, produção, instalação e serviços associados. De acordo com Tripp Martin, diretor de 
qualidade da Peterson Spring, a "QS-9000 não é uma norma, mas ela contém a norma ISO 9001 ; seus requisitos são mais amplos que a ISO 9001." De fato, a QS9000 é muito mais rigorosa. Martin constata que "há 137 "musts"(requisitos obrigatórios) no documento da ISO 9001 e 300 "musts" no documento da QS9000." (Struebing, 1996)

A QS-9000 foi criada para ser um padrão mundial de Sistema da Qualidade para Chrysler, Ford, GM e todos os seus fornecedores. Ela está sendo adotada, também, por vários fabricantes de caminhões tais como Freightliner, Mack Trucks, Navistar, Paccar, Transportation Manufacturing Corp. and Volvo/GM. Antes do surgimento desta norma, cada uma dessas empresas possuía seu próprio padrão de sistema de qualidade. Assim, tinhamos: Supplier Quality Assurance (Chrysler), Q 101 (Ford) e Targets for Excellence (GM). Todos eles serão, agora, substituídos pela QS-9000.

A QS-9000 está dividida em três seções:

I - Requisitos da ISO 9001 acrescidos de requisitos suplementares;

II - Requisitos adicionais, específicos do setor automotivo;

III-Requisitos específicos da Chrysler, Ford e GM.

\subsection{A ISO 9001 adaptada}

A primeira seção da QS-9000 repete literalmente o texto da ISO 9001 , na sua versão revisada em 1994, acrescentando, em cada item, os requisitos do setor automotivo. Assim, dos vinte requisitos do sistema da qualidade que compõem a norma ISO 9001 , dezessete receberam acréscimos no texto da QS-9000. Apenas os requisitos 4.3 Análise critica do contrato, 4.7 Controle de produto fornecido pelo cliente e 4.8 Identificação e rastreabilidade de produto foram mantidos inalterados.

Anexamos uma tabela comparativa, para possibilitar uma visão genérica dos principais acréscimos que a QS-9000 apresenta em relação à ISO 9001 . Essa tabela foi elaborada com base em uma apostila de apresentação da QS-9000 distribuída pelas montadoras Ford e GM para seus principais fornecedores no Brasil. Ela contém, do lado esquerdo, os requisitos da ISO 9001 e, do lado direito, os acréscimos contidos na QS-9000.

\subsection{A introdução da melhoria contínua}

Enquanto a primeira seção da QS9000 é apenas uma reprodução da ISO 9001 com algumas adaplações para o setor automotivo, é na segunda e terceira seções que vamos encontrar diferenças realmente significativas entre as normas.

A seção II da QS-9000 trata dos requisitos específicos do setor automobilístico, que são: processo de aprovação da produção de peças (PPAP), melhoria contínua e capacidade de manufatura. 


\section{PRODUÇÃO}

Em relação ao PPAP, foi elaborado um manual cujos requisitos devem ser cumpridos pelos fornecedores. Estes devem possuir um banco de dados completo, referente ao processo de produção de peças que notifique todas as mudanças efetuadas.

Entretanto, a parte mais interessante e inovadora da QS-9000 refere-se ao requisito de melhoria contínua. Alguns dos requerimentos por ela definidos em relação à melhoria contínua são:

- Difusão da filosofia através de toda a organização;

- Desenvolvimento de planos específicos para a melhoria contínua;

- Identificação das oportunidades de melhoria continua;

- Demonstração do conhecimento das técnicas para a melhoria contínua.

Kume (1993) afirma que o que falta à série ISO 9000 é a noção da melhoria contínua, impossibilitando que um efetivo gerenciamento da qualidade seja alcançado pela simples adoção destas normas. Porém, segundo Corrigan (1994), isso não é uma deficiência, já que este não é o objetivo da série ISO 9000 . Ela foi projetada apenas para garantir a adequação de um sistema de qualidade e sua observância dentro da organização.

Por outro lado, a melhoria contínua é a base do modelo japonês conhecido como Total Quality Management (TQM). Pfau (1989) define TQM como sendo "a busca da melhoria continua de produtos e serviços, o que requer a participação de todos na organização". Roesch (1994) afirma que a principal diferença entre a ISO 9000 e o modelo japonês é que, enquanto aquela se atém à conformidade aos padrões, este visa à melhoria contínua, na qual a qualidade torna-se um alvo móvel, definida em relação aos competidores.

Nesse ponto, portanto, a QS-9000 aproxima-se mais do TQM do que da ISO 9000. Como diz Hilary (1996), seu objetivo é "desenvolver sistemas de qualidade fundamentais que proporcionam a melhoria contínua, enfatizando a prevenção de defeitos e a redução da variação e perda na cadeia de fornecedores. Em resumo, sua meta é melhorar a qualidade e aumentar a produtividade para que as Três Grandes possam competir com mais sucesso com os carros construidos pelos japoneses, coreanos e europeus." Diante disso, tornase necessário um enfoque muito mais abrangente que o proposto pela série ISO 9000 .

O terceiro item da seção II refere-se à capacidade de manufatura. Este item prevê a utilização de times interdepartamentais para o desenvolvimento das instalações, processos e equipamentos em conjunto com o processo de Planejamento Avançado da Qualidade (AQP). O "layout" da planta deve maximizar a produtividade e devem ser utilizadas técnicas de avaliação de erros. Em relação às ferramentas utilizadas, o fornecedor 


\section{PRODUÇÃO}

deve garantir que seu projeto, fabricação, inspeção, manutenção e reparos sejam conduzidos de modo satisfatório.

\subsection{Requisitos específicos das montadoras}

A terceira seção trata dos requisitos especificos da Chrysler, Ford e GM. Estes requisitos devem ser acordados entre cada montadora e seus fornecedores.

Segundo Sérgio Pleszko, Supervisor de Assistência Técnica para Fornecedores da Ford do Brasil, a existência desta terceira seção visa dar liberdade para que cada montadora mantenha seus próprios padrões em relação a nomenclatura, desenhos e simbologia.

Entre os requisitos específicos da FORD citados por ele estão a definição de itens de controle e características criticas, que são fatores que podem afetar a segurança de um veículo em operação ou alguma determinação do governo. Além disso, a Ford define padrões de manufatura para tratamento térmico, hidrogenização e toxicologia dos materiais empregados, através de manuais especificos para cada um destes itens. Através do Quality Operating System (QOS), a montadora avalia o desempenho de seus fornecedores utilizando critérios como a quantidade de peças rejeitadas em partes por milhão (PPM).

Assim como ocorre com a ISO 9000 , o processo de certificação da QS-9000 será conduzido por terceiros. Para isto, a Task
Force (equipe composta por representantes das três montadoras encarregada de elaborar a QS-9000) reconheceu alguns órgãos como acreditadores. Estes acreditadores são responsáveis por qualificar os organismos certificadores de acordo com os requisitos estabelecidos para conduzir uma auditoria da QS-9000. Há ainda os órgãos treinadores, reconhecidos para oferecer cursos de apresentação e consultoria para os fornecedores.

\section{Os impactos da QS-9000 no setor automotivo}

Segundo Paul C. Fortlage, vicepresidente do United States Registrar Accreditation Board (RAB), dentre as várias vantagens trazidas pela $Q S-9000$, destacam-se duas. "Primeiro, havia fornecedores que ofereciam o mesmo produto para mais de uma montadora. Os diferentes requisitos dos sistemas de qualidade de cada montadora criavam complicações para os fornecedores. QS9000 foi a maneira de unificar os requisitos das Três Grandes." Desta maneira, a QS-9000 procura alcançar, no setor automotivo, o que a ISO 9000 temse proposto a fazer nas indústrias em geral, ou seja, unificar os diversos padrões de sistema de garantia da qualidade existentes. $O$ segundo ponto apontado por Fortlage é que "a mudança para a QS9000 foi feita para economizar dinheiro. Era caro para cada montadora manter seu próprio "staff" de auditores de fornecedores." (Brecka, 1995) 


\section{PRODUÇÃO}

As montadoras já estabeleceram prazos finais para que seus fornecedores adotem a QS-9000. Assim, a Ford fixou o dia 31 de janeiro de 1997 como data máxima para que seus fornecedores realizem uma auditoria de primeira parte (aquela que o fornecedor se auto-avalia). Por outro lado, até 31 de julho de 1997 e 31 de dezembro de 1997, os fornecedores de Chrysler e GM, respectivamente, deverão ter efetuado uma auditoria de terceira parte, ou seja, serem avaliados por um órgão certificador.

Apesar de poucas empresas terem obtido a certificação até o momento, a expectativa é que, nessa primeira etapa, mais de 14000 (quatorze mil) empresas sejam certificadas em todo o mundo. Esses seriam apenas os fornecedores diretos ou de primeira-ordem. Entretanto, apesar de não ser exigida a certificação de fornecedores de segunda-ordem, a expectativa é que mais de 40000 (quarenta mil) deles busquem o certificado. " $O$ resultado final é que o novo sistema será imposto ao longo de toda a cadeia de fornecedores", conclui Hilary (1996).

\section{A QS-9000 no Brasil}

No Brasil, assim como no resto do mundo, as montadoras têm procurado seguir os passos de suas matrizes, exigindo que seus fornecedores adotem 0 padrão QS-9000. O início das discussões em relação ao tema se deu no ambiente do Comitê de Qualidade da Associação Nacional dos Fabricantes de Veículos Automotores (ANFAVEA) há cerca de um ano e meio atrás.
Segundo Pleszko, que representa a Ford neste organismo, a estratégia definida pelos indústrias automobilísticas foi iniciar a implantação da QS-9000 em nosso país através do PPAP (Processo de Aprovação da Produção de Peças). Foi criado o Instituto da Qualidade Automotiva (IQA), uma entidade sem fins lucrativos, responsável por difundir a QS9000 entre os fornecedores. Na feira de autopeças, realizada em outubro de 1995 no Centro de Convenções do Anhembi em São Paulo, o IQA lançou o manual do PPAP.

A versão completa da QS-9000 em português está em fase final de elaboração e deverá ser eviada para homologação da Task Force ainda no primeiro semestre de 1996. Tão logo seja aprovada, ela será distribuida para os fornecedores brasileiros. Entretanto, estes já receberam a versão em inglês da norma, para que já possam ir adiantando o processo de implantação do sistema de qualidade de acordo com as especificações da QS-9000.

É interessante observar que a adoção da QS-9000 no Brasil não se restringe apenas às subsidiárias da Ford e GM. Muitas outras montadoras, entre elas Volkswagen, Mercedes-Benz e Volvo, também estão tomando parte neste processo. Pleszko afirma que esta tendência de "abrir" a QS-9000 a outras empresas não está sendo verificada apenas no Brasil, mas em todo o mundo.

\section{Conclusão}

Apesar de estar baseada na ISO 9000 , a QS-9000 se propõe a ir além desta 


\section{PRODUÇÃO}

norma. Como afirma Monkhouse (1996), a QS-9000 faz o que a ISO deveria ter feito há algum tempo atrás: aliar ao gerenciamento global dos controles dos sistemas de qualidade algumas técnicas de qualidade, apesar dele acreditar que nem todos os fornecedores precisem adotar todas as técnicas para merecerem confiança.

Esta proposta está presente, principalmente, na segunda seção da QS9000 , quando ela introduz o conceito de melhoria contínua. Entretanto, deve-se considerar a proposição de Kume (1993), que afirma ser impossivel normatizar-se melhoria continua. Segundo ele, esta tentativa foi feita também pela ISO ao elaborar a norma ISO 9004-4 Guia para Melhoria Contínua. Apesar de ser uma norma excelente, em sua opinião ela não consegue atingir todos os seus propósitos, não porque contenha erros, mas porque nem tudo pode ser alcançado através da normatização.

Em relação aos prazos para certificação, é muito provável que eles sejam estendidos. A versão brasileira da norma ainda não foi concluída, enquanto que na Europa, o primeiro certificado da QS-9000 só foi emitido em janeiro de 1996. A empresa a recebê-lo foi a britânica Dunlop-Topy Wheels, fabricante de rodas de aço para automóveis e caminhões leves. (Perella, 1996)

Entretanto, isso não significa que exista a possibilidade da QS-9000 fracassar em seus objetivos. Ressalta-se que o caráter compulsório da norma obriga todos os fornecedores a adequaremse às suas exigências, o que realmente está sendo feito.

Acreditamos que um fator facilitador do processo de adaptação à QS-9000 seja o fato de que a maioria das empresas do setor automobilístico já possui um sistema da qualidade implementado. Muitas delas adotam os padrões das montadoras como Q 101 (Ford), Targets for Excellence (GM), etc., enquanto que muitas outras baseiam-se nas normas da série ISO 9000 .

Finalmente, vale destacar que a tendência é que cada vez mais empresas, montadoras e fornecedores diretos, passem a exigir a QS-9000 de seus fornecedores. Como diz John Sonnenstein, gerente de qualidade da Dunlop-Topy, "se os três maiores fabricantes de automóveis reconheceram sua necessidade, (...) é apenas uma questão de tempo para que as outras montadoras adotem também este requerimento e compreendam o processo envolvido". (Perella, 1996)

Recebido em: 20/12/97

Aceito em: 03/05/98

Publicado em: 27/07/98

\section{Referências}

BRECKA, Jon QS-9000: Activities Heatin Up Quality Progress, April 1995, p. 20-21 


\section{PRODUÇĀO}

CORRIGAN, James P. Is ISO 9000 the Path to TQM? Quality Progress, May 1994, p.33-36

FORD e GM Apostila de introdução e apresentação da QS-9000 para fornecedores São Paulo, fevereiro de 1996

HILARY, Rachel Behind the Stars and Stripes: Quality in the USA Quality Progress, January 1996, p.31-35

KUME, Hitoshi Management by Quality Appendix Three - Quality Management by ISO 9000 and by TQC Tokyo, 1993

MONKHOUSE, Richard Packaged for QS 9000? Quality Today, March 1996, p. 14

PERELLA, Maxine Top gear for QS 9000 Quality Today, March 1996, p.1011
PFAU, L.D. Total Quality Management gives companies a way to enhance position in global market Industrial Engineering, April 1989

PLESZKO, Sérgio Supervisor de Assistência Técnica para Fornecedores FORD do Brasil Entrevista pessoal, São Paulo, 30 de abril de 1996

ROESCH, Sylvia M. A. ISO 9000: caminho para a qualidade total? Revista de Administração, São Paulo v.29, n.4, p.13-21, out/dez 1994

STRUEBING, Laura 9000 Standards? Quality Progress, January 1996, p.23-28 
PRODUÇÃO

\begin{tabular}{|ll|} 
REQUISITOS DAISO 900 & ADIÇOESDA QS-9000 \\
\hline 4.1 Responsabilidade da Administração & 4.1 .2 .3 - Interfaces Organizacionais \\
& 4.1 .4 - Planejamento de negócios \\
& 4.1 .5 - Análise dos dados pela organização \\
& 4.1 .6 - Satisfação do cliente \\
\hline 4.2 Sistema da Qualidade & \\
& 4.2 .3 - Planejamento da Qualidade \\
- Planejamento Avançado da Qualidade - & APQP \\
- Times interdepartamentais \\
- Revisão de Viabilidade Técnica \\
- FMEA \\
- Planos de Controle
\end{tabular}

4.3 Análise crítica de contrato

4.4 Controle de projeto

4.4.2 - Habilidades requeridas

4.4.4 - Dados de entrada de projeto

(complemento)

REQUISITOS DA ISO 9001

4.4 Controle de projeto

.5 Controle de documentos e dados

4.6 Compras

.7 Produtos fornecidos pelo cliente

4.8 Identificação e rastreabilidade do produto

\section{ADIÇÕES DA QS-9000}

4.4.5 - Dados de saida de projeto (complemento)

4.4.7 - Verificação de projeto

(complemento)

4.4.9 - Alterações de projeto

4.5.1 - Documentos de referência

4.5.2 - Especificações de Engenharia

4.6.1 - Materiais aprovados pelo cliente para produção

4.6.2 - Desenvolvimento de sub

fornecedores e pontualidade de entrega 


\section{PRODUÇÃO}

\begin{tabular}{|c|c|}
\hline 4.9 Controle do processo & $\begin{array}{l}\text { 4.9 - Regulamentações Governamentais } \\
\text { para segurança e meio ambiente } \\
\text { - Designação de caracteristicas críticas } \\
\text { - Manutenção preventiva } \\
\text { 4.9.1 - Monitoração do processo e instruções } \\
\text { para o operador } \\
\text { 4.9.2 - Requisitos sobre capacidade } \\
\text { preliminar do processo PPK } \\
\text { 4.9.3 - Requisitos sobre capacidade do } \\
\text { processo produtivo CPK } \\
\text { 4.9.4 - Alterações nos requisitos de } \\
\text { desempenho do processo produtivo } \\
\text { 4.9.5 - Verificação de "set up" } \\
\text { 4.9.6 - Alteraç̃̃es de processo } \\
\text { 4.9.7 - Itens de aparência }\end{array}$ \\
\hline 4.10 Inspeçðes e testes & $\begin{array}{l}\text { 4.10.1 - Critérios de aceitação - zero defeito } \\
\text { 4.10.2 - Inspeção de recebimento } \\
\text { 4.10.3 - Inspeção de processo }\end{array}$ \\
\hline 4.11 Equipamentos de teste, medição e inspeção & $\begin{array}{l}\text { 4.11.3 - Registros de aferição dos } \\
\text { equipamentos de inspeção, medição e testes } \\
\text { 4.11.4 - Análise dos Sistemas de Medição } \\
\text { MSA }\end{array}$ \\
\hline 4.12 Controle e identificação sobre a situação do material & $\begin{array}{l}\text { 4.12.1 - Localização do produto } \\
\text { 4.12.2 - Verificação suplementar }\end{array}$ \\
\hline 4.13 Controle de não conformidades & $\begin{array}{l}\text { 4.13.2 - Revisão e disposição de produtos } \\
\text { não conformes } \\
\text { 4.13.3 - Controle de produto retrabalhado } \\
\text { 4.13.4 - Autorização de Engenharia }\end{array}$ \\
\hline 4.14 Ação corretiva e preventiva & $\begin{array}{l}\text { 4.14.1 - Métodos para resolução de } \\
\text { problemas } \\
\text { 4.14.2 - Análise de peças retornadas }\end{array}$ \\
\hline $\begin{array}{l}\text { 4.15 Manuseio, armazenamento, embalagem, } \\
\text { conservação e entrega }\end{array}$ & $\begin{array}{l}\text { 4.15.3 - Estoque } \\
\text { 4.15.4 - Normas de embalagem } \\
\text { 4.15.6 - Monitoramento do desempenho das } \\
\text { entregas } \\
\text { Programa de produção } \\
\text { Sistema de notificą̧ão de envio }\end{array}$ \\
\hline 4.16 Registros da Qualidade & $\begin{array}{l}\text { 4.16 - Conservação dos Registros da } \\
\text { Qualidade }\end{array}$ \\
\hline 4.17 Auditorias internas da Qualidade & 4.17 - Inclusão do Ambiente de Trabalho \\
\hline
\end{tabular}


PRODUÇÃO

\begin{tabular}{|ll|}
\hline 4.18 Treinamento & $\begin{array}{l}4.18 \text { - Treinamento como um fator } \\
\text { estratégico }\end{array}$ \\
\hline 4.19 Serviços & $\begin{array}{l}4.19 \text { - "Feed Back" das informações do-- } \\
\text { campo }\end{array}$ \\
\hline Técnicas Estatisticas & $\begin{array}{l}4.20 .2 \text { - Procedimentos } \\
\text { Seleção de ferramentas estatisticas } \\
\text { Conhecimento dos conceitos estatísticos } \\
\text { básicos }\end{array}$ \\
\hline
\end{tabular}

Tabela 1 - Comparação entre ISO 9001 e QS-9000 